\title{
Effect of the environment on the risk of respiratory disease in preweaning dairy calves during summer months
}

\author{
A. P. Louie, ${ }^{*}$ J. D. Rowe, $\dagger$ W. J. Love, ${ }^{*}$ T. W. Lehenbauer, ${ }^{\star} \dagger$ and S. S. Aly ${ }^{*}{ }^{1}$ \\ *Veterinary Medicine Teaching and Research Center, School of Veterinary Medicine, University of California, Davis, Tulare 93274 \\ †Department of Population Health and Reproduction, School of Veterinary Medicine, University of California, Davis, Davis 95616
}

\begin{abstract}
Heat stress has the potential to adversely affect the physiology, passive immunity, and growth of preweaning dairy calves, increasing their risk of respiratory disease. The effect of heat stress on the risk for bovine respiratory disease (BRD) may be mediated in part through housing, ventilation, and management factors. As a result, differences may exist in meteorological measures recorded in the calf-rearing area (macroenvironment) and within a calf's enclosure (microenvironment). The objective of this prospective cohort study was to evaluate and compare the association between exposure to temperature and humidity measured at the macro- and microenvironment, and BRD in preweaning dairy calves; a secondary objective was to evaluate the correlation between the macro- and microenvironment. A cohort of 252 calves from 4 premises in central San Joaquin Valley, California (CA), was followed and evaluated for development of respiratory disease using the CA BRD scoring system for preweaning dairy calves, a standardized and validated scoring system. During this time, the meteorological conditions of the calf-rearing area and the within-hutch environment were measured and showed a significant correlation with regard to temperature and humidity. Mixed effects logistic regression and survival analysis were used to analyze the association between the exposures daily environmental measures of temperature, humidity, and temperaturehumidity index (THI) and the outcome BRD, adjusted for dairy premises, calf age, sex, and breed. Results showed a significant positive association between daily maximum temperature and BRD in both the calf's macroenvironment [odds ratio $=1.121(95 \%$ confidence interval $(\mathrm{CI})=1.029-1.222)]$ and microenvironment $[$ odds ratio $=1.203(95 \% \mathrm{CI}=1.020-1.418)]$. Estimated hazard rates also showed a significant positive association between BRD and daily maximum temperature in
\end{abstract}

Received August 20, 2017.

Accepted July 11, 2018.

${ }^{1}$ Corresponding author: saly@ucdavis.edu both the macroenvironment [hazard ratio $=1.127(95 \%$ $\mathrm{CI}=1.053-1.206)]$ and microenvironment [hazard ratio $=1.119(95 \% \mathrm{CI}=1.047-1.197)]$. In contrast, we found no association between daily maximum humidity in a calf's microenvironment and BRD. Daily maximum THI within the hutch was significantly associated with only the rate of $\mathrm{BRD}$ cases [hazard ratio $=1.070(95 \%$ $\mathrm{CI}=1.003-1,141)]$ but not the odds of occurrence of BRD. Maximum THI is estimated using temperature and humidity, which in California's hot and dry summers may limit variability in THI, explaining its weaker significant association with risk of BRD (or lack of association with odds of BRD) compared with models for maximum temperature in this study. Calves exposed to high day temperatures and relatively low humidity may be experiencing heat stress that predisposes to BRD. Results of the current study suggest that heat abatement efforts should address heat stress at the microenvironment level to mitigate BRD in calves. Further research should investigate strategies to improve calf hutch systems, including hutch materials and design that may optimize ventilation, provide ample shade, spacing, cleanliness, and protection from heat.

Key words: bovine respiratory disease, dairy calf, heat stress, microenvironment, macroenvironment

\section{INTRODUCTION}

Bovine respiratory disease (BRD) affects both adult and young, dairy and beef cattle, but has the most effect through shipping fever in beef calves and enzootic calf pneumonia in dairy calves (Callan and Garry, 2002). In US dairy production systems, BRD has been reported as the second most common illness in preweaning calves, at $18.1 \%$ morbidity, and the most common illness in weaned calves, at $11.2 \%$ morbidity (USDA-APHIS, 2012). Furthermore, BRD was associated with $22.5 \%$ of total mortality in preweaning heifers and $46.5 \%$ of total mortality in weaned heifers (USDA-APHIS, 2007). Impairment of the respiratory tract immunity due to interactions between viral and bacterial pathogens, the latter often opportunistic and commonly isolated from 
the upper respiratory tract of healthy cattle (Griffin et al., 2010), may be compounded by environmental and management factors. The resulting bronchopneumonia can lead to nasal and ocular discharge, depression, anorexia, fever, and cough (Callan and Garry, 2002; Autio et al., 2007; Griffin et al., 2010).

Prevention of BRD in dairy calves focuses on improving the calf's ability to respond to infectious challenge through adequate transfer of passive immunity at birth and, in turn, through good colostrum management and appropriate nutrition. In addition, BRD prevention should include mitigating disease exposure and transmission through vaccination and biosecurity practices, as well as appropriate housing with adequate ventilation (Gorden and Plummer, 2010). Environmental factors, such as ventilation, ambient temperature and humidity, and levels of airborne irritants, such as ammonia, can also affect a calf's risk of BRD (Lago et al., 2006). Investigation of the effect of heat stress on BRD is valuable, as the potential to influence the calf environment through heat-abatement interventions exists.

Heat stress may have adverse effects on calf passive immunity and lead to stress-induced immunosuppression (Stott et al., 1976; Carroll and Forsberg, 2007). The thermoneutral range for calves, estimated at 10 to $25^{\circ} \mathrm{C}$ at 1 mo of age, with an upper limit of $30^{\circ} \mathrm{C}$ for maximum acclimated temperature, is narrower than for adult animals (Wathes et al., 1983; Davis and Drackley, 1998). Above the thermoneutral zone, animals expend energy to release heat from the body through increased respiration, which may result in reduced feed intake, efficiency, and impaired immune function as the calf's energy resources are diverted (Lammers et al., 1996; Mitlöhner et al., 2002). Preweaning dairy calves are commonly raised individually in hutches, which vary in their styles including material, insulation, ventilation, area, and protection from wind and solar radiation. As a result, differences may exist in what a calf experiences in its hutch (microenvironment) compared with the surrounding area (macroenvironment; Macaulay et al., 1995; Lago et al., 2006; Carter et al., 2014). Differences between the macro- and microenvironment may lead to inaccurate assessment of environmental stressors and their effect on calf health.

Preventing BRD in calves contributes to maximizing economic efficiency due to its negative long-term effects on growth and performance (Waltner-Toews et al., 1986; Donovan et al., 1998; Stanton et al., 2012). Although effects of heat stress on calf physiology and growth have been investigated (Neuwirth et al., 1979; Spain and Spiers, 1996; Mitlöhner et al., 2002; Broucek et al., 2009), the contrast in effects of the macro- and microenvironment temperature and humidity, particularly on the risk of BRD in preweaning dairy calves, has not been evaluated. Understanding the effect of heat stress on BRD will be critical for recommending best management practices to maximize production and welfare (Nardone et al., 2010; IPCC, 2014).

The objective of our study was to evaluate the association between exposure to temperature and humidity measured in the macro- and microenvironment and the risk of BRD in preweaning dairy calves during the summer in central San Joaquin Valley, California (CA). A secondary objective was to estimate the correlation between the macro- and microenvironment of preweaning dairy calves.

\section{MATERIALS AND METHODS}

\section{Study Design}

A prospective cohort study was conducted on 3 dairies and 1 calf ranch in the central San Joaquin Valley, California, between April and September 2013. Healthy Holstein and Jersey dairy calves were enrolled after being identified for a different study to validate an onfarm scoring system for diagnosis of respiratory disease in preweaning dairy calves (Aly et al., 2014; Love et al., 2016). The study protocol was approved March 21, 2013, by the University of California, Davis Institutional Animal Care and Use Committee. Only healthy calves enrolled for the scoring system validation study were followed up for the purpose of this study until BRD diagnosis or censoring at or soon after weaning. A sample size of 40 to 75 calves was deemed necessary to estimate the prevalence of BRD in study herds with varying calf herd sizes between 200 and 6,000, with a bound on error of estimation of $10 \%$ and assumed prevalence of $25 \%$ (Scheaffer et al., 2012).

\section{Study Herds}

The study herds were described in detail elsewhere (herds 1 to 4 in Love et al., 2016). Briefly, calves were enrolled from 3 dairies and a calf ranch that raised calves from 3 additional local dairies in central San Joaquin Valley, CA. Herds 1, 2, 3, and 4 raised approximately $200,350,600$, and 1,050 preweaning calves of both sexes, and breeds were composed of Holstein (herds 1 and 3), Jersey (herd 2), or both (herd 4). The participating facilities were privately owned and all study activities were performed with owner consent.

\section{Calf Management}

Calves were housed individually in wood hutches arranged either in a single row (herd 1) or several rows (herds 2 and 4) on the study dairies, or housed in metal 
Table 1. Vaccination and enrollment schedule for preweaning calves raised on 4 premises in California's San Joaquin Valley in a study of the association between environment and bovine respiratory disease (numbers of calves present and eligible for enrollment each day were estimated from records)

\begin{tabular}{|c|c|c|c|c|c|c|c|c|c|c|}
\hline \multirow[b]{2}{*}{ Premises } & \multicolumn{4}{|c|}{ Vaccination age, $\mathrm{d}$} & \multirow{2}{*}{$\begin{array}{l}\text { Starting age } \\
\text { for enrollment } \\
\text { eligibility, d }\end{array}$} & \multicolumn{2}{|c|}{$\begin{array}{l}\text { Estimated } \\
\text { calves/d }\end{array}$} & \multicolumn{2}{|c|}{$\begin{array}{c}\text { Dates of } \\
\text { follow-up, mo/d/yr }\end{array}$} & \multirow{2}{*}{$\begin{array}{l}\text { Number of visits } \\
\text { (mean number } \\
\text { of weekly visits) }\end{array}$} \\
\hline & $1-3$ & $4-30$ & $31-60$ & $>60$ & & Total & Eligible & Start & End & \\
\hline 2 & & & $70^{1}$ & $110^{2}$ & 16 & 350 & 267 & $6 / 27 / 13$ & $9 / 12 / 13$ & $40(3.6)$ \\
\hline 3 & $2^{1}$ & $15,^{3} 30^{3}$ & & $75^{3}$ & 42 & 600 & 216 & $7 / 23 / 13$ & $8 / 28 / 13$ & $22(4.3)$ \\
\hline 4 & $3^{1}$ & $14,,^{2} 28^{2}$ & & & 42 & 1,050 & 310 & $4 / 29 / 13$ & $8 / 6 / 13$ & $56(4)$ \\
\hline
\end{tabular}

${ }^{1}$ Vaccination using Inforce3 (modified-live infectious bovine rhinotracheitis, parainfluenza ${ }_{3}$, bovine respiratory syncytial virus intranasal vaccine, Zoetis, Florham Park, NJ).

${ }^{2}$ Vaccination using Bovi-shield 4 (modified-live bovine viral diarrhea virus type 1, infectious bovine rhinotracheitis, parainfluenza 3 , bovine respiratory syncytial virus; Zoetis).

${ }^{3}$ Vaccination using Bovi-shield Gold 5 (modified-live bovine viral diarrhea virus types 1 and 2, infectious bovine rhinotracheitis, parainfluenza 3 , bovine respiratory syncytial virus; Zoetis).

hutch enclosures arranged in several rows on the calf ranch (herd 3). The wood hutches were constructed in triplicate, with each unit composed of 3 individual hutches elevated above ground level and measuring approximately $1.47 \mathrm{~m}$ (depth) by $0.80 \mathrm{~m}$ (width) by 1.35 $\mathrm{m}$ (height, from floor to highest point of roof) in herds 1 and 4 , and $1.52 \mathrm{~m}$ (depth) by $0.81 \mathrm{~m}$ (width) by 1.27 $\mathrm{m}$ (height) in herd 2. Nose-to-nose contact was possible between adjacent calves in wood hutches. Wood hutches had slatted floors with no additional bedding. Herds 1 and 4 had a concrete flush canal beneath hutches; waste from herd 2 calf hutches drained into the dirt below, resulting in mud surfaces below and behind the hutches. Calves housed in individual metal hutch enclosures measuring $2.44 \mathrm{~m}$ (deep) by $0.91 \mathrm{~m}$ (wide) by $1.57 \mathrm{~m}$ (height) had packed-sand bedding and were not elevated from the ground. The metal hutches were separated such that nose-to-nose contact was not possible. All hutches had a solid wood (herds 1, 2, and 4) or corrugated metal roofing (herd 3) for shade, with most of the facilities having additional shade structures over all of the hutches (herds 1 and 4) or portions of the hutch areas (herd 3).

Calves from all herds typically received $4 \mathrm{~L}$ of colostrum from cows and heifers within 6 to $12 \mathrm{~h}$ after birth. Calves were given 1.5 (herd 2) to $2 \mathrm{~L}$ (herds 1, 3, and 4) of pasteurized waste milk or milk replacer twice daily. In addition, calves were offered a starter grain mix ad libitum daily and provided fresh water by bucket (herds 1,3 , and 4 ) or water line with a nipple drinking device for each calf (herd 2). Typical vaccination protocols in the study herds included intranasal modified live viral vaccine against bovine herpesvirus-1, parainfluenza-3, and bovine respiratory syncytial virus (Inforce3; Zoetis, Florham Park, NJ), and parenteral modified live viral vaccine against bovine viral diarrhea-1, bovine herpesvirus-1, parainfluenza-3, and bovine respiratory syncy- tial virus (Bovi-shield 4; Zoetis). Typical vaccination schedules are summarized in Table 1. Range of study herd weaning ages were 80 to 85 (herd 1), 110 to 130 (herd 2), and 60 to $65 \mathrm{~d}$ (herd 3 and 4), but variation in management ultimately determined time of removal from hutch to group pens.

\section{Selection Criteria}

Calves were selected using a list generated from a random number table, applied to the ordered arrangement of individual calf hutches within rows (Microsoft Excel 2010, Microsoft Corp., Redmond, WA). Enrollment took place between April 29, 2013, and August 1, 2013. Heifer and bull calves were eligible for enrollment in the study if they did not have a record of antibiotic treatment within the last $10 \mathrm{~d}$ and were not vaccinated within the last $14 \mathrm{~d}$. The age range of eligible calves depended on each facility's weaning protocol and vaccination schedule.

Inclusion criteria also included calves being healthy, defined as having a normal thoracic auscultation and ultrasound findings over all lung fields, having a negative score using a validated system (the CA BRD scoring system for preweaning calves), and having no previous treatment record by the calf caretakers on the study premises (Aly et al., 2014; Love et al., 2014, 2016). The scoring system (Appendix Figure A1) is composed of 6 clinical signs with each sign assigned a 0 if normal or a numeric score if abnormal, which included any detection of abnormal ocular discharge (2 points) or nasal discharge (4 points), observation of spontaneous cough (2 points), and change in head or ear disposition (5 points). The scoring system calls also for assessing the quality of respiration in comparison to surrounding calves, and calves with a higher respiratory rate or greater difficulty breathing were assigned a score $(2$ 
points). However, in the current study we used a cutoff of 50 breaths per minute to quantify elevated rate (Spain and Spiers, 1996; Radostits et al., 2000; Divers and Peek, 2007). Finally, elevated rectal temperature (2 points) was considered as being equal to or greater than $39.2^{\circ} \mathrm{C}\left(102.5^{\circ} \mathrm{F}\right)$, and was only measured for calves that would potentially achieve a composite score equal to or greater than 5 by including the evaluation of rectal temperature. Scores for the 6 clinical signs were added, with a clinical score of 5 or greater representative of BRD; a minimum of 0 and a maximum of 17 could be assigned using this system.

Calves were excluded if they had abnormal thoracic auscultation or abnormal findings on thoracic ultrasound. Briefly, auscultation was considered to be abnormal if rales, crackles, wheezing, moist lung sounds, pleural friction, alveolar snapping, or muffled lung sounds were detected. For the ultrasound exam, hair was clipped between the olecranon, the caudal angle of the scapula, and the transverse process of the 10th thoracic vertebra on each side of the thorax. The skin was cleaned and moistened using alcohol before ultrasound examination (Ibex Pro Ultrasound, $8-5 \mathrm{MHz} 66$ $\mathrm{mm}$ linear probe; E.I. Medical Imaging, Loveland, CO). Abnormal ultrasound findings were classified into 4 categories of lesions or artifacts indicative of BRD complex: small comet tails, large comet tails, consolidation, and abscesses. Comet tails are resonance artifacts that are characteristically hyperechogenic. Small comet tails described artifacts originating in the pleura that were $<5 \mathrm{~mm}$ wide. Large comet tails described reverberation artifacts originating from the pleura or parenchyma that were $\geq 5 \mathrm{~mm}$ wide. Consolidation was determined if hypoechoic regions of lung parenchyma were observed, typically containing 1 or more hyperechoic air bronchograms. Abscesses appeared as well demarcated areas with hyperechoic borders containing hypoechoic or heterogeneous material. Thoracic ultrasound findings were classified as abnormal if any of the following were detected: numerous small comet tails in multiple fields observed along with pleural pathology, multiple large comet tails, focal or extensive consolidation, or abscesses (Buczinski et al., 2014).

\section{Analytical Methods}

Following enrollment, clinical observations to assess for signs of respiratory disease were performed 2 to 4 weekdays each week, depending on the number of calves and facilities involved at a given time during the study period. On follow-up days, trained personnel evaluated calves for BRD using the BRD scoring system used at enrollment, with a cutoff of 5 or greater was representa- tive of BRD (Aly et al., 2014; Love et al., 2014, 2016). Calves remained in the study until they were evaluated as a BRD case or until removal from hutch.

\section{Macro- and Microenvironment Measures}

To evaluate the macroenvironment, a single data logger (weather station) measuring temperature and relative humidity (HOBO U23 Pro, Onset Computer Corporation, Bourne, MA) was placed out of direct sunlight within the calf-rearing area of each facility and secured to the pole of a shading structure approximately $3 \mathrm{~m}$ above the ground. The weather station recorded temperature and relative humidity every $10 \mathrm{~min}$ and was left in place for the approximate duration of each facility's participation in the study. The data from each facility were summarized by day to produce the daily mean, maximum, and minimum temperature and relative humidity, which were then matched to each location's calf records by follow-up date. Although calves were enrolled in the mornings, herd visits to assess the current study calves for BRD occurred in the afternoon, after attending to the scoring system validation study. Hence, environmental measures were linked to the same day's calf BRD status given that the minimum temperature occurred before sunrise of the same day and the maximum temperature occurred before BRD assessment on the same day. A temperature-humidity index (THI) was also calculated for each 10-min reading to derive daily mean, maximum, and minimum THI utilizing a formula based on a National Oceanic and Atmospheric Administration (NOAA, 1976) study:

$$
\mathrm{THI}=\mathrm{T}-(0.55-0.0055 \times \mathrm{RH}) \times(\mathrm{T}-58),
$$

where $\mathrm{T}=$ temperature read by the data logger in degrees Fahrenheit and $\mathrm{RH}=$ relative humidity in percent. Daily NOAA summary data were used for study dates when weather station data were not available due to device malfunction or enrollment of calves before placement of a location's weather station. Data from NOAA were also used for the placement, removal, or malfunction date of each facility's weather station, as placement or removal occurred during day time, resulting in summary data skewed without a full 24 -h record. The NOAA data used were averaged from 2 stations in the study county that best encompassed the locations of the study facilities. The NOAA summary data available provided mean, maximum, and minimum daily temperatures, but only mean daily humidity (reported as dew point, and converted to relative humidity for comparability; NOAA Relative Humidity Calculator; https://www.wpc.ncep.noaa.gov/html/dewrh.shtml). 
Hence, it was not possible to accurately calculate THI values for NOAA data without more frequent temperature and concurrent humidity readings available for each day. Due to the limitations encountered in using NOAA data for humidity and THI values, and the number of weather station dates for which NOAA data would have been substituted (32.1\% of total study days across all study facilities), temperature was the only environmental measure investigated for the macroenvironment. Maximum values were chosen as the exposure of interest for the macroenvironment rather than minimum or mean values due to the attenuating effect of averaging measurements over a 24 -h period and the focus on heat stress during summer.

To evaluate the microenvironment, enrolled calves had a data logger assigned and secured within the hutch at standing flank level, enclosed within a plastic pipe apparatus with approximately 12 drilled ventilation holes $(0.9525 \mathrm{~cm}$ diameter $)$ to protect the device from contact with urine, feces, or oral secretions from the calf. The apparatus was capped on top and left open at the bottom. Dependent on the limited number of devices (between 20 at start of the study and 32 toward the end of the study period) and availability, calves could have been assigned a data logger shortly after enrollment or at any later date during followup. When a data logger became available due to a calf exiting the study (becoming a case or censored at weaning), the excess device was randomly assigned to another enrolled calf. A random number table was used to identify the next recipient calf (Microsoft Excel 2010). Resulting data were summarized by calf and day to yield mean, maximum, and minimum temperature, relative humidity, and THI, as previously described for the macroenvironment measures; similarly, only maximum values were used for analysis. Device placement, removal, or malfunction dates were also lacking a full $24 \mathrm{~h}$ of recording; on these dates, the mean of other calves' microenvironment data from the same premises on the same day were used. When other calves with full microenvironment data on the same premises and day were not available, the prior day's data from the same calf's data logger were used.

\section{Statistical Analysis}

Correlation Between Macro- and Microenvironment Measurements. The Spearman rank correlation coefficient was estimated for macro- and microenvironment temperature and relative humidity values recorded on the same premises, day, and time (measurements taken every $10 \mathrm{~min}$ by data loggers). Spearman rank correlation was also estimated for macroenvironment and NOAA temperature and humidity summary values by day (mean, maximum, and minimum temperature, mean humidity). The Spearman rank correlation coefficient ranges from -1 to 1 , with 0 indicating no correlation, -1 perfect negative correlation, and 1 perfect positive correlation. The coefficient was also used to test the null hypothesis that macroand microenvironment measures were independent. The following ranges were used to interpret the correlation coefficient: $<40 \%=$ poor; 41 to $75 \%=$ fair to good; $>75 \%=$ excellent (Fleiss et al., 2003).

BRD Incidence Density Rates. Bovine respiratory disease incidence density rates (IDR) were estimated for all the study calves, stratified by herd, and the 75th percentile of the environmental measure estimated within the calf hutches during the study period. Specifically, IDR were estimated for $<83.3$ and $\geq 83.3$ THI, $<37.2$ and $\geq 37.2^{\circ} \mathrm{C}$, and $<81.9$ and $\geq 81.9 \%$ humidity. Incidence density rates were based on calf days at risk from enrollment to BRD score positive status using equation 1 :

$$
\mathrm{IDR}=(\text { no. of BRD cases }) /(\text { sum of calf-days at risk }) .
$$

Mixed Effects Logistic Regression: Macroenvironment. A mixed effects logistic regression model was used to measure the magnitude of the association between the macroenvironment's daily maximum temperature and BRD. Explanatory variables considered in the full model included the fixed effects macroenvironment temperature (MAXTEMP), dairy (3 dummy variables), age, breed, and sex. A random intercept $\left(u_{I D}\right)$ for individual calf was included to account for repeated measurements of BRD score and compared using the Akaike information criterion (AIC) to models with other random effect structures including random effects for dairy and time. A lower AIC value was deemed a better fit. A tentative model with a single random intercept for calf can be summarized in equation 2 :

$$
\begin{gathered}
\operatorname{Logit}[\operatorname{Pr}(\mathrm{BRD})]=\beta_{0}+\beta \mathrm{X}_{\text {Dairy }}+\beta \mathrm{X}_{\mathrm{Age}}+\beta \mathrm{X}_{\text {Breed }} \\
+\beta \mathrm{X}_{\mathrm{Sex}}+\beta \mathrm{X}_{\text {MAXTEMP }}+u_{I D}
\end{gathered}
$$

where $\beta_{0}$ is the intercept and $\beta \mathrm{X}$ are the respective fixed effects. The variable "dairy" was categorized into herds 1, 2, 3, and 4, with herd 1 as referent. The variables "breed" and "sex" were similarly categorical, with Holstein and female referents, respectively. Linearity of $\log$ odds for the continuous variables "age" and MAXTEMP was tested using the Box-Tidwell method (Box and Tidwell, 1962). The continuous variable "age" violated the linearity of log odds assumption, and was categorized into age ranges 16 to 55,56 to 69,70 to 83 , 
and 84 to $126 \mathrm{~d}$, with the 16 to $55 \mathrm{~d}$ range as referent. A manual backward variable elimination process was used with variables eliminated if $P>0.05$. Competing models were compared using the AIC for non-nested models or compared using the likelihood ratio test if nested. The ratio of odds was estimated for each variable in the final model as the exponent of the respective variable's coefficient and interpreted as the change in odds of BRD given a unit change in the continuous variable or in comparison to the referent for categorical variables. The odds ratio (OR) ranges from 0 to infinity, with confidence intervals estimated for each variable's OR at the $5 \%$ level of significance. An OR's $95 \%$ confidence interval that included 1 was interpreted as no significant association between the respective variable and BRD. An OR with an upper 95\% confidence limit less than 1 was interpreted as protective, whereas a lower limit greater than 1 as a risk factor for BRD.

Mixed Effects Logistic Regression: Microenvironment. Mixed effects logistic regression models were used to measure the association between the microenvironment's MAXTEMP, maximum humidity (MAXHUMID), maximum THI (MAXTHI), or both MAXTEMP and MAXHUMID on the outcome BRD. As described for the macroenvironment, variables in the full model for the microenvironment included dairy, age, breed, and the microenvironment measure as fixed effects, with a random intercept for calf compared with other random effect structures. Sex was not included as a variable in the microenvironment analyses, as the subset of calves with microenvironment data contained only 13 male calves in 3 herds, with a BRD outcome occurring in 2 of the male calves from a single location, which limited model convergence. Continuous variables (age and microenvironment measures) were similarly assessed for linearity of their log odds, and variable selection was carried out as described for the macroenvironment model. The independent variable MAXTHI violated the linearity of the log odds and was categorized into $\leq 80$ or $>80$. Initially, a cutoff of 72 was considered, a common reference point for heat stress in mature dairy cattle, but models would not converge due to the sparsity of daily maximum THI data below 72 (which ranged from 71 to 91 ) given the summer temperatures and humidity in the study region. Instead, a cutoff of 80 was used, the lower end of a range for moderate heat stress (Armstrong, 1994). The OR were estimated and interpreted as for the macroenvironment logistic regression model.

Mixed effects logistic regression models were used to estimate the odds of BRD occurring given temperature and humidity measurements taken at the macro- and microenvironment level. However, these models do not provide information about the hazard rates of $\mathrm{BRD}$, or more specifically, the hazard over time for BRD occurring given the same temperature and humidity measurements in the macro- and microenvironment; the latter was modeled using survival analysis.

Survival Analysis: Macroenvironment. A Cox proportional hazard regression model was used to estimate the hazard of $\mathrm{BRD}$ given macroenvironment MAXTEMP. Censor dates were assigned to calves based on the date a calf was weaned. The proportional hazard assumption that any 2 calves' BRD hazards were independent of time (and hence proportional) was tested using the scaled Schoenfeld residuals for noncensored calves' covariates regressed over time. A significant nonzero slope coefficient was used to identify variables that violated the proportional hazard assumption. The full Cox model to estimate the hazard of BRD contained variables dairy, age, breed, sex, and MAXTEMP specified as described for logistic regression, and summarized in equation 3 :

$$
\begin{aligned}
\lambda[t, \mathrm{X}(t)] & =\lambda_{0}(t) \exp \left(\beta \mathrm{X}_{\text {Dairy }}+\beta \mathrm{X}_{\mathrm{Age}}+\beta \mathrm{X}_{\mathrm{Sex}}\right. \\
& \left.+\beta \mathrm{X}_{\text {Breed }}+\beta \mathrm{X}_{\text {MAXTEMP }}\right),
\end{aligned}
$$

where $\lambda_{0}$ is a nonnegative unspecified baseline hazard, and $t$ is time. Models were run utilizing a robust variance estimate (clustered sandwich estimator) that adjusted for possible within-cluster correlation for dairy (Williams, 2000). A manual backward variable elimination process was used, with variables eliminated at $P>$ 0.05. The AIC was used to compare competing models. The hazard ratio (HR) was estimated for each of the final models' variables, as the exponent of the respective variable's coefficient and interpreted as the change in hazard for BRD given a unit change in continuous variables or in comparison to the referent for categorical variables. The HR ranges from 0 to infinity, with confidence intervals estimated for each variable's HR at the 5\% level of significance. An HR's 95\% confidence interval that included 1 was interpreted as no significant association between the respective variable and BRD. An HR with an upper $95 \%$ confidence limit less than 1 was interpreted as protective, or a lower limit greater than 1 as a risk factor for BRD.

Survival Analysis: Microenvironment. Cox proportional hazard regression models were used to estimate the hazard of BRD given microenvironment MAXTEMP, MAXHUMID, MAXTHI, and both MAXTEMP and MAXHUMID. Censor dates were assigned to calves based on the date a calf was weaned. For each model, the proportional hazard assumption was assessed as described for microenvironment survival analysis. Other predictors included dairy, age, and breed as described for logistic regression; the vari- 
able sex was not included for any microenvironment analysis, as previously described. Models were run utilizing a robust variance estimate (clustered sandwich estimator) that adjusted for possible within-cluster correlation for dairy. A manual backward elimination procedure was implemented with variables eliminated at $P>0.05$. The AIC was used to compare competing models. The HR were estimated and interpreted as for the macroenvironment survival analysis model. All analyses were performed using commercial statistical software (Stata/IC 13.1, StataCorp LLC, College Station, TX) and a 5\% level of significance observed for statistical inferences.

\section{RESULTS}

The climate of California's central San Joaquin Valley during the summer can be characterized as typically hot and dry, with several months achieving daily maximum temperatures of over $37.8^{\circ} \mathrm{C}\left(100^{\circ} \mathrm{F}\right)$. The range of temperatures observed by the participating facilities during the study period is summarized by month in Table 2.

A total of 257 randomly selected calves were eligible for enrollment and follow-up in the study. For models estimating the effect of macroenvironment on BRD, a total of 5 calves were excluded. Four calves had unknown age, and 1 calf within this group also did not have sex recorded, and 1 additional calf was lost to follow-up. Data from a total of 252 calves remained for analyses of the macroenvironment. The majority of calves were female $(79.8 \%)$ and Holstein $(65.1 \%)$; by dairy, calves were $29.0 \%$ from herd $1,19.4 \%$ from herd $2,11.5 \%$ from herd $3,40.1 \%$ from herd 4 . The age range at enrollment was 16 to $82 \mathrm{~d}$.

A subset of 94 calves had a data logger placed in their hutch as early as the day after enrollment or at a later point during follow-up to measure temperature and humidity of their microenvironment. The duration of time that calves had a data logger (between placement and censoring or becoming a BRD case) ranged between 2 and $65 \mathrm{~d}$ (mean $24.9 \mathrm{~d}$ duration and median $21 \mathrm{~d}$, with only a single calf in the final analyses having the logger for only $2 \mathrm{~d}$ ), based on random assignment of a data logger upon availability. Device recording failures or corrupt data files occurred in 16 of the data loggers, leaving 78 calves with microenvironment data. Of those 78 calves, a total of 3 calves were excluded; these 3 calves achieved a CA BRD score $\geq 5$ during follow-up, but a data logger was placed after this event. Hence, data from 75 calves remained for analyses of the microenvironment data, with 13 having a data logger from the day after enrollment until study exit. Of these calves, the majority were female $(82.7 \%)$ and Jersey
Table 2. Range of macroenvironment weather station temperatures observed April through September 2013 in the central San Joaquin Valley, California

\begin{tabular}{lcc}
\hline Month & $\begin{array}{c}\text { Minimum } \\
\text { temperature, }{ }^{\circ} \mathrm{C}\left({ }^{\circ} \mathrm{F}\right)\end{array}$ & $\begin{array}{c}\text { Maximum } \\
\text { temperature, }{ }^{\circ}{ }^{\circ} \mathrm{C}\left({ }^{\circ} \mathrm{F}\right)\end{array}$ \\
\hline April $^{2}$ & $13.0(55.4)$ & $33.5(92.3)$ \\
May & $7.7(45.8)$ & $37.6(99.6)$ \\
June & $11.5(52.7)$ & $41.9(107.4)$ \\
July & $14.0(57.2)$ & $41.5(106.7)$ \\
August & $12.6(54.6)$ & $42(107.6)$ \\
September $^{2}$ & $15.2(59.4)$ & $40.1(104.2)$ \\
\hline
\end{tabular}

${ }^{1}$ Weather station data from herd 1 was excluded due to possible erroneous device recordings exceeding regional National Oceanic and Atmospheric Administration (https://www.ncdc.noaa.gov/cdo-web/) maximum temperatures during the observed study period.

${ }^{2}$ Range includes data from study dates, not full month.

( $56.0 \%)$; by dairy, calves were $18.7 \%$ from herd $1,38.7 \%$ from herd $2,9.3 \%$ from herd 3 , and $33.3 \%$ from herd 4 .

Among the study calves with macroenvironment data, $30.0 \%$ of calves were considered BRD positive during their follow-up; within the subset of calves that had microenvironment data, $29.3 \%$ of calves were considered BRD positive during their follow-up. The BRD cases in the study calves with macroenvironment data and those with microenvironment data broken down by month, dairy, sex, and breed are summarized in Table 3.

Table 3. Total number of bovine respiratory disease (BRD) cases identified by the California BRD scoring system in study calves with macroenvironment data $(\mathrm{n}=252)$ and in study calves that had microenvironment data $(\mathrm{n}=75)$ followed repeatedly over the preweaning period on 4 premises in the central San Joaquin Valley, California, and stratified by dairy, sex, breed, and month

\begin{tabular}{lcc}
\hline Item & $\begin{array}{c}\text { Number of BRD } \\
\text { macro cases, }{ }^{1} \%(\mathrm{SE})\end{array}$ & $\begin{array}{c}\text { Number of BRD } \\
\text { micro cases, }{ }^{2} \%(\mathrm{SE})\end{array}$ \\
\hline Dairy & & \\
Herd 1 & $9,3.57(0.01)$ & $1,1.30(0.01)$ \\
Herd 2 & $24,9.52(0.02)$ & $10,13.30(0.04)$ \\
Herd 3 & $10,3.97(0.01)$ & $3,4.00(0.02)$ \\
Herd 4 & $33,13.10(0.02)$ & $8,10.70(0.04)$ \\
Sex & & \\
Female & $66,26.19(0.03)$ & $20,26.70(0.05)$ \\
Male & $10,3.97(0.01)$ & $2,2.70(0.02)$ \\
Breed & & \\
Holstein & $35,13.89(0.02)$ & $6,8.00(0.03)$ \\
Jersey & $41,16.27(0.02)$ & $16,21.30(0.05)$ \\
Month & & \\
April & 0 & 0 \\
May & $2,0.79(0.01)$ & 0 \\
June & $25,9.92(0.02)$ & $4,5.30(0.03)$ \\
July & $20,7.94(0.02)$ & $6,8.00(0.03)$ \\
August & $18,7.14(0.02)$ & $3,4.00(0.02)$ \\
September & $11,4.37(0.01)$ & $9,12.00(0.04)$ \\
Total & $76,30.16(0.03)$ & $22,29.30(0.05)$ \\
\hline
\end{tabular}

${ }^{1}$ BRD cases in study calves $(n=252)$ with macroenvironment data. ${ }^{2} \mathrm{BRD}$ cases in the subset of calves $(\mathrm{n}=75)$ with microenvironment data. 


\section{Macro- and Microenvironment Measures}

An approximated $32.1 \%$ of the cumulative weather station dates (macroenvironment) across all 4 locations were missing due to device malfunction, placement, or removal. Herd 1 was missing $5.8 \%$ of its recorded macroenvironment dates, herd 2 was missing $26.9 \%$, herd 3 was missing $7.9 \%$, and herd 4 was missing $68 \%$. Observed calf follow-up dates within the missing ranges for macroenvironment data were substituted by regional NOAA values (https://www.ncdc.noaa.gov/cdo-web/). Herd 1's weather station device was also determined to be reading erroneously high, producing daily maximum temperatures that were frequently out of range of the highest NOAA recording $\left(42^{\circ} \mathrm{C}\right.$ or $\left.107.6^{\circ} \mathrm{F}\right)$ for the region during the study period (approximately $49.4 \%$ of daily maximum temperatures were above $107.6^{\circ} \mathrm{F}$ in herd 1, compared with $5.4 \%$ in herd 3 , and 0 in herd 2 and 4 ). The records from herd 1 were therefore excluded from macroenvironment analyses, resulting in useable data from 179 calves. These 179 calves were $74.3 \%$ female and $50.8 \%$ Holstein; by dairy, calves were $27.4 \%$ from herd $2,16.2 \%$ from herd 3 , and $56.4 \%$ from herd 4 .

An approximated $13.8 \%$ (125 of 904) of microenvironment follow-up dates had environmental recordings that were unreliable due to device malfunction or skewed on dates of device placement and removal. These dates were substituted with an average of other calves' microenvironment data from the same premises on the same day. When no other calves were available with full microenvironment data on the same premises and day but the calves had a prior day's data, the prior day's values were used to substitute $(1.7 \%$, or 15 followup dates). When neither of these options were available, the follow-up records were excluded from analyses (2.0\%, or 18 follow-up dates). Records with a daily maximum temperature past the highest recording from NOAA weather stations for the region during the study period $\left(42^{\circ} \mathrm{C}\right.$ or $\left.107.6^{\circ} \mathrm{F}\right)$ were considered erroneous and also excluded (1.2\%, or 11 follow-up dates), yielding a total of 73 calves for microenvironment analyses. These 73 calves were $82.2 \%$ female and $42.5 \%$ Holstein; by dairy, calves were $17.8 \%$ from herd $1,39.7 \%$ from herd $2,8.2 \%$ from herd 3 , and $34.2 \%$ from herd 4 .

\section{Correlation Between Macro- and Microenvironment Measures}

The Spearman rho coefficient for macroenvironment and microenvironment temperature readings, paired by location, date, and 10-min recording time interval, was excellent (rho 0.976; $P<0.001$ ). Similarly, the correlation between macro- and microenvironment relative humidity readings, matched as above, was excellent (rho $0.974 ; P<0.001$ ). The correlation coefficient for weather station and NOAA daily mean temperature readings was 0.890 , daily minimum temperature 0.908 , daily maximum temperature 0.714 , and daily mean relative humidity 0.488 , with $P<0.001$ across all comparisons.

\section{$B R D I D R$}

Bovine respiratory disease IDR for calves by study herd, MAXTHI, MAXTEMP, and MAXHUMID measured within calf hutches are summarized in Table 4 . Maximum daily temperature and THI recordings in a calf's microenvironment greater than $37.2^{\circ} \mathrm{C}\left(99^{\circ} \mathrm{F}\right)$ and 83.3 THI, respectively, were associated with an increased incidence of BRD. In contrast, daily maximum humidity recordings in a calf's microenvironment greater than $86.4 \%$ were associated with a decrease in incidence of BRD.

\section{Mixed Effects Logistic Regression}

Macroenvironment. The final mixed effects logistic regression model for the odds of BRD as predicted by macroenvironment MAXTEMP is summarized in Table 5. Calves enrolled in referent herd 2 had the lowest odds of becoming a BRD case compared with the remaining herds, though only herd 4 was significant, whereas in all study herds the odds of becoming a case increased as calves grew older. Calves that ranged in age between 70 and $83 \mathrm{~d}$ old had 3.7 times the odds of BRD compared with calves 16 to 55 d old (referent). Similarly, calves that were 84 to $126 \mathrm{~d}$ old had 4.2 times the odds of BRD compared with the referent calves. Finally, the odds of a BRD case increased by $12.1 \%$ with every degree Celsius increase in MAXTEMP in the macroenvironment.

Microenvironment. The final mixed effects logistic regression models for the odds of $\mathrm{BRD}$ predicted by microenvironment measures (MAXTEMP, MAXHUMID, MAXTHI, and both MAXTEMP and MAXHUMID) are summarized in Table 6 . The effect of age was significant in only the MAXHUMID model, with the odds of becoming a BRD case increasing with calf age (in all other models, variable was dropped from the final model when $P>0.05$ ). The odds of BRD in calves increased approximately $20.3 \%$ with every degree Celsius increase in the maximum temperature inside the hutch. In addition, the magnitude of effect of MAXTEMP on the odds of BRD remained consistent and significant even when both daily maximum temperature and maximum relative humidity were in the same model. The magnitude of the association between MAXTEMP and 
Table 4. Incidence density rates (IDR) for bovine respiratory disease (BRD) based on the CA BRD scoring system, stratified by herd and the microenvironmental measures ${ }^{1}$ maximum temperature (MAXTEMP), humidity (MAXHUMID), and temperature-humidity index (MAXTHI) for preweaning dairy calves on 4 premises in the central San Joaquin Valley, California

\begin{tabular}{|c|c|c|c|c|c|}
\hline \multirow[b]{3}{*}{ Variable } & \multirow[b]{3}{*}{ Calf-days at risk } & \multicolumn{4}{|c|}{ CA BRD scoring system } \\
\hline & & \multirow[b]{2}{*}{ BRD cases } & \multirow[b]{2}{*}{ IDR, cases/d } & \multicolumn{2}{|c|}{$95 \%$ CI } \\
\hline & & & & Lower & Upper \\
\hline \multicolumn{6}{|l|}{ Herd } \\
\hline 1 & 463 & 1 & 0.002 & $<0.001$ & 0.015 \\
\hline 2 & 705 & 10 & 0.014 & 0.008 & 0.026 \\
\hline 3 & 67 & 3 & 0.045 & 0.014 & 0.139 \\
\hline 4 & 435 & 8 & 0.018 & 0.009 & 0.037 \\
\hline Overall & 1,670 & 22 & 0.013 & 0.009 & 0.02 \\
\hline \multicolumn{6}{|l|}{ MAXTEMP } \\
\hline$<37.2^{\circ} \mathrm{C}^{2}$ & 1,159 & 12 & 0.010 & 0.006 & 0.018 \\
\hline$\geq 37.2^{\circ} \mathrm{C}$ & 494 & 9 & 0.018 & 0.010 & 0.035 \\
\hline \multicolumn{6}{|l|}{ MAXHUMID } \\
\hline$<86.4 \%$ & 1,256 & 17 & 0.014 & 0.008 & 0.022 \\
\hline$\geq 86.4 \%$ & 397 & 4 & 0.010 & 0.004 & 0.027 \\
\hline \multicolumn{6}{|l|}{ MAXTHI } \\
\hline$<83.3$ & 1,225 & 15 & 0.012 & 0.007 & 0.020 \\
\hline$\geq 83.3$ & 428 & 6 & 0.014 & 0.006 & 0.031 \\
\hline
\end{tabular}

${ }^{1}$ Stratified using the 75 th percentile MAXTEMP, MAXHUMID, and THI measured within calf hutches during the study period.

${ }^{2} 37.2^{\circ} \mathrm{C}$ converts to $99^{\circ} \mathrm{F}$.

BRD in the calves' microenvironment was greater than that in the macroenvironment (20.3 vs. $12.1 \%$ ). The microenvironment measures MAXHUMID and MAXTHI were not significant predictors of BRD.

\section{Survival Analysis}

Macroenvironment. Cox regression model results for the hazard of BRD as predicted by macroenvironment MAXTEMP are summarized in Table 7 .
Effects of herd and age on the hazard rates of BRD were significant, with herd 2 calves experiencing the least risk compared with the remaining herds whereas older calves had greater hazard of BRD compared with younger calves, specifically a $0.7 \%$ increase in hazard rate of $\mathrm{BRD}$ every day calves grew older. Male calves had $42 \%$ less hazard rate of BRD compared with female calves. Maximum daily temperature was a significant predictor of the hazard of $\mathrm{BRD}$, with an approximately $12.7 \%$ increase in hazard rate of BRD with every de-

Table 5. Final mixed effects logistic regression model for the odds of bovine respiratory disease (BRD) predicted by macroenvironment maximum temperature (MAXTEMP) in preweaning dairy calves from 3 premises $^{1}$ in the central San Joaquin Valley, California $(\mathrm{n}=179)$

\begin{tabular}{|c|c|c|c|c|}
\hline Variable & Odds ratio & SE & $P$-value & $95 \%$ CI \\
\hline \multicolumn{5}{|l|}{ Dairy } \\
\hline Herd 2 & Referent & - & - & - \\
\hline Herd 3 & 1.701 & 0.683 & 0.185 & $0.775,3.735$ \\
\hline Herd 4 & 1.991 & 0.591 & 0.020 & $1.113,3.561$ \\
\hline \multicolumn{5}{|l|}{$\mathrm{Age}^{2}$} \\
\hline $16-55$ & Referent & - & - & - \\
\hline $56-69$ & 2.579 & 1.445 & 0.091 & $0.860,7.736$ \\
\hline $70-83$ & 3.706 & 2.027 & 0.017 & $1.268,10.826$ \\
\hline $84-126$ & 4.248 & 2.452 & 0.012 & $1.371,13.167$ \\
\hline MAXTEMP ${ }^{3}{ }^{\circ} \mathrm{C}$ & 1.121 & 0.049 & 0.009 & $1.029,1.221$ \\
\hline Model $\mathrm{AIC}^{4}$ & 602.844 & & & \\
\hline
\end{tabular}

${ }^{1}$ Weather station data from herd 1 excluded due to potential erroneous device recordings that exceeded range of regional National Oceanic and Atmospheric Administration (https://www.ncdc.noaa.gov/cdo-web/) temperatures during the observed study period.

${ }^{2}$ The variable age was categorized and measured in days.

${ }^{3}$ Maximum daily temperature $\left({ }^{\circ} \mathrm{C}\right)$.

${ }^{4}$ Akaike information criterion. 
EFFECT OF ENVIRONMENT ON CALF PNEUMONIA

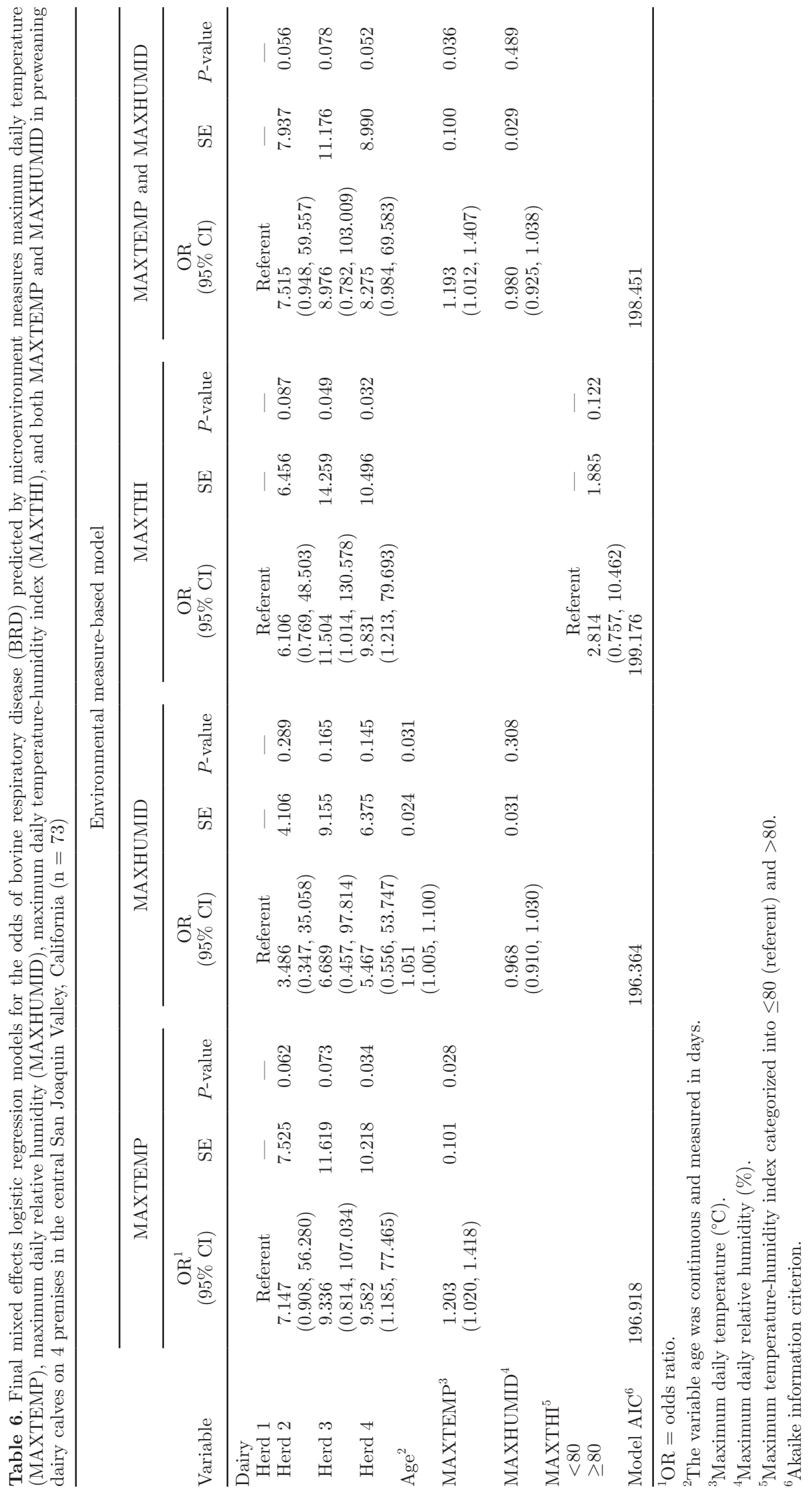


gree Celsius increase in maximum temperature inside a hutch. The median time until BRD $(\mathrm{n}=76)$ was 18.5 $\mathrm{d}$, with a minimum $1 \mathrm{~d}$ and a maximum $64 \mathrm{~d}$.

Microenvironment. The Cox regression model results for the hazard of BRD as predicted by microenvironment measures (MAXTEMP, MAXHUMID, MAXTHI, and both MAXTEMP and MAXHUMID) are presented in Table 8. The effect of herd was significant with the exception of herd 2 compared with herd 1 in the MAXHUMID model. Effects of age and breed on BRD were significant across all models. Jersey calves had significantly greater hazard rates of BRD compared with Holstein calves, approximately twice the hazard rate. Daily maximum temperature was a significant predictor of the hazard rate of $\mathrm{BRD}$ in calves, with an approximately $11.9 \%$ increase in risk of BRD with every degree Celsius increase in maximum temperature inside a hutch or an $11.6 \%$ increase adjusting for the effect of maximum humidity. Maximum humidity was not a significant predictor of the hazard of BRD. Daily maximum THI was a significant predictor of the hazard of $\mathrm{BRD}$, with an approximately $7.0 \%$ increase in risk of BRD with every unit increase. In addition, when maximum humidity and maximum temperature were used to predict the hazard rate of BRD in the same model, both maintained similar magnitude of effect, but only maximum temperature was significant. The median time until BRD $(\mathrm{n}=22)$ was $14.5 \mathrm{~d}$, with a minimum of $2 \mathrm{~d}$ and a maximum of $37 \mathrm{~d}$.

\section{DISCUSSION}

Data from our prospective cohort study suggested a significant association between daily maximum temperature and $\mathrm{BRD}$ in both the macro- and microenvi- ronment of preweaning dairy calves. In addition, BRD may be more accurately predicted by daily maximum temperature measured within the calf's hutch compared with that recorded at the calf-rearing area. Finally, our study showed a significant association between maximum THI as measured within the hutch and hazard of $\mathrm{BRD}$, which may be driven more by the effect of maximum temperature rather than humidity, given that the later was not significantly associated with BRD.

The current study showed that dairy calves exposed to high daily maximum temperatures are at greater odds of developing $\mathrm{BRD}$, and that the magnitude of this association increased when predicted by daily maximum temperatures at the microenvironment within a hutch compared with the macroenvironment of the calf raising area. A difference in the effect of maximum temperature recorded in the calf's macro- and microenvironment on the odds of BRD may be explained by the fact that conditions recorded in close proximity to the calf are likely to be more representative of each calf's exposure. Despite a high correlation between macro- and microenvironment measurements of temperature, factors that may result in different maximum temperature readings in a calf's macro- compared with microenvironment include hutch material, orientation, position within the hutch area, or presence of supplemental shading. Changes in the macroenvironment temperature may be associated with disproportional changes in the microenvironment. With differing management styles of calves and variations in hutch setups accounted for by the variable dairy, housing calves in a hutch system appears to alter their environment. Calves may be exposed to factors such as heat, differences in heat conduction based on hutch material and structure, emissions produced by decomposition of calf

Table 7. Final Cox regression model for the hazard rates of bovine respiratory disease (BRD) predicted by macroenvironment maximum temperature (MAXTEMP) in preweaning dairy calves from 3 premises ${ }^{1}$ in the central San Joaquin Valley, California $(\mathrm{n}=179)$

\begin{tabular}{|c|c|c|c|c|}
\hline Variable & Hazard ratio & Robust SE & $P$-value & $95 \% \mathrm{CI}$ \\
\hline \multicolumn{5}{|l|}{ Dairy } \\
\hline Herd 2 & Referent & - & - & - \\
\hline Herd 3 & 2.917 & 0.377 & $<0.001$ & $2.264,3.757$ \\
\hline Herd 4 & 2.680 & 0.125 & $<0.001$ & $2.445,2.937$ \\
\hline $\operatorname{Age}^{2}$ & 1.007 & 0.002 & $<0.001$ & $1.004,1.011$ \\
\hline \multicolumn{5}{|l|}{ Sex } \\
\hline Female & Referent & - & - & - \\
\hline Male & 0.583 & 0.037 & $<0.001$ & $0.515,0.660$ \\
\hline MAXTEMP,${ }^{3}{ }^{\circ} \mathrm{C}$ & 1.127 & 0.039 & 0.001 & $1.053,1.206$ \\
\hline Model $\mathrm{AIC}^{4}$ & 582.687 & & & \\
\hline
\end{tabular}

${ }^{1}$ Weather station data from herd 1 excluded due to systematic erroneous device recording that exceeded range of regional National Oceanic and Atmospheric Administration (https://www.ncdc.noaa.gov/cdo-web/) maximum temperatures during the observed study period.

${ }^{2}$ The variable age was continuous and measured in days.

${ }^{3}$ Maximum daily temperature $\left({ }^{\circ} \mathrm{C}\right)$.

${ }^{4}$ Akaike information criterion. 
EFFECT OF ENVIRONMENT ON CALF PNEUMONIA

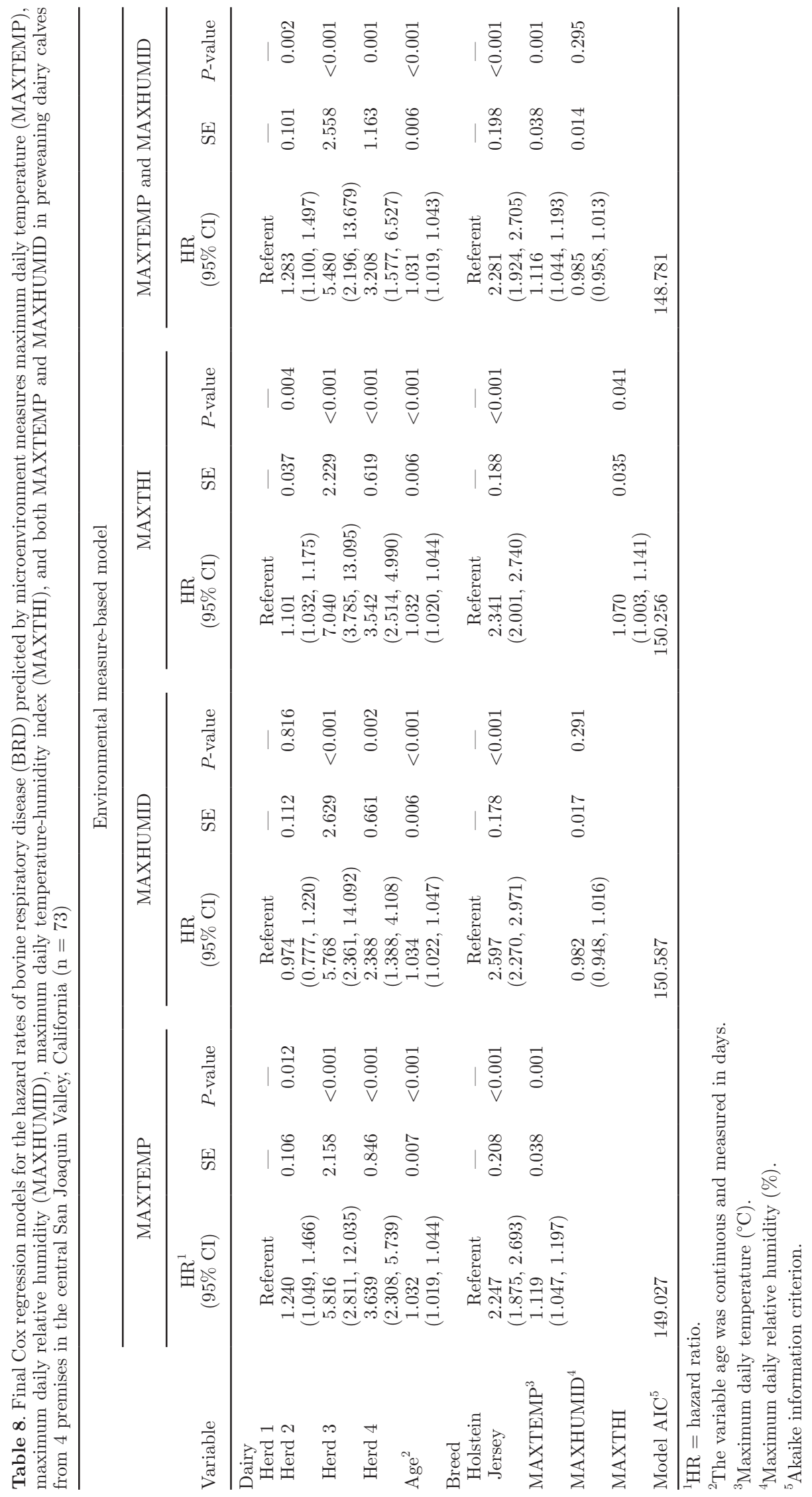


manure and urine, such as ammonia, and quality of ventilation contributing to the increased risk of $\mathrm{BRD}$ detected by the microenvironment maximum temperature model. The concept of calf enclosures functioning as microclimates compared with the surrounding area has been documented previously (Lago et al., 2006).

Daily maximum relative humidity was not associated with an increase in OR or HR of BRD at the microenvironment level. Peak humidity regularly occurred in the early morning hours when temperatures and THI were typically lowest and may not have contributed to stress and disease susceptibility of the calves as an independent variable. Although high relative humidity, particularly in confinement housing, can be an environmental risk factor associated with respiratory disease, calves in outdoor individual hutches may not experience similar ventilation, pathogen density and transmission, and air quality issues (Callan and Garry, 2002; Gorden and Plummer, 2010). Bertagnon et al. (2011) found higher monocyte blood counts and lower alveolar giant macrophages in tracheobronchial lavage fluid in calves exposed to a combination of higher temperature and lower humidity, suggesting hot and dry climates, such as the one in the current study, could suppress the respiratory immune response (Roland et al., 2016). However, when peak daily THI, a heat-stress index incorporating both temperature and humidity, was used as a microenvironment predictor for hazard of BRD in the current study, it was significant. The weaker association between maximum THI and BRD compared with maximum temperature suggests that, in regions with hot and dry summer months, as in central San Joaquin Valley, daily maximum temperatures may be a more useful indicator of heat stress affecting hutch-raised calves; hence, it may be a better BRD predictor for animals under these conditions than THI. Additionally, temperature and humidity may function as independent environmental stressors at the hutch level given that neither variable's estimates changed when both were in the same model. In a study quantifying heat stress thresholds related to milk production to develop a heat-stress function adapted to the likely increased susceptibility of Holstein cows to heat stress due to genetic selection, daily maximum temperature and minimum humidity were deemed the most critical variables for quantifying heat stress (Ravagnolo et al., 2000). Studies linking calves born in warmer climates to decreased feed intake and weight gain (West, 2003) and extreme high or low average daily temperatures to increased calf mortality (Stull et al., 2008) might corroborate the effect of elevated daily maximum temperatures on BRD found in our study. In contrast, a study evaluating factors associated with neonatal dairy calf mortality in hot, arid climates, found that exposure of calves to temperatures exceeding their thermoneutral zone occurred through most of the year but was not reflected in mortality or physiological observations (Mellado et al., 2014). However, calves in the latter study were only followed from birth to $21 \mathrm{~d}$ of age and data on morbidity were not reported. Windeyer et al. (2014) found that the odds of being treated for BRD in dairy heifers born in winter were 2.6 times greater than heifers born in summer, which might indirectly suggest elevated temperatures or potential heat stress did not have a strong effect on $\mathrm{BRD}$; however, differences in climate, weather conditions, and other management factors that may vary by season may contribute to the association of BRD and cooler months and do not preclude an effect of heat stress.

Over the study's follow-up period, an increase in microenvironment maximum THI was associated with an increase in risk of BRD, approximately a $7 \%$ increase in risk for every 1 unit increase in THI. In contrast, with every unit increase in microenvironment maximum temperature, the risk of BRD increased $12 \%$. Given the significant effect of maximum temperature but no significant association between maximum humidity and BRD, it is possible that calculation of THI dilutes the effect of maximum temperature and results in an underestimate of its effect, especially given the opposing directionality of the associations between humidity and BRD as well as maximum temperature and BRD. Maximum humidity was also associated with lower IDR for BRD cases when the daily maximum humidity was greater than or equal to $86.4 \%$ (the 75 th percentile of its distribution) in a calf's microenvironment compared with when maximum daily humidity was less than $86.4 \%$. With higher levels of maximum humidity, air moisture is expected to increase, which may improve the calf's breathing and or loosen mucus in its respiratory tract.

The interplay of environmental measures and their unification into a single estimate such as THI could explain the study findings during California's summer months, specifically high temperatures paired with lower humidity, yielding a more moderate THI that underestimates the heat stress experienced by calves. Similarly, low temperatures paired with higher humidity, typically detected overnight in the region, also yield a more moderate THI. In a generally low humidity climate, such as the central San Joaquin Valley during the summer, maximum THI as measured within the calf hutch may not achieve the variability or range necessary to show a significant effect in analysis and, therefore, may not be as appropriate of an indicator for the effect of heat stress on BRD in calves in the study region. Heat stress is caused by a combination of variables, including temperature, humidity, solar radia- 
tion, wind speed, and precipitation, but using an index such as THI for assessing heat stress in animals is more common due to the accessibility of data (Bohmanova et al., 2007). Different species manage ambient temperature differently depending on moisture in the air (Bohmanova et al., 2007). A well-used reference level for optimal comfort and production in mature dairy cows reported in literature is a THI of 71 or 72 or lower, with varying classifications of stress at higher values (Johnson et al., 1962; Armstrong, 1994). However, despite its widespread use for cattle and other animals, THI as an index is limited by assuming all animals respond the same to environmental stressors and not taking into account other environmental effects such as air movement, solar radiation, or cow-specific effects, such as age and breed (Hammami et al., 2013). The THI thresholds for heat stress in calves have not been well defined, and calves likely experience and tolerate heat differently than adult cattle due to differences in body volume and surface area and level of heat production from metabolic processes. Additionally, the standard THI calculation may not be as accurate in different climates, where thresholds of heat stress may also vary; Bohmanova et al. (2007) determined a THI weighted toward humidity was more effective for cattle in a humid region, such as Georgia, and a THI with more emphasis on temperature was more effective for cattle in a less-humid region, such as Arizona. The variable efficacy of standard THI application in regard to climate and animal-specific factors, such as age or stage of production, could also have contributed to THI being a weaker environmental predictor of BRD in dairy calves in our study. A study by Dikmen and Hansen (2009) concluded that dry-bulb temperature measures were nearly as good predictors of cow rectal temperatures and heat stress as a THI index. Other studies on heat stress effects on production in dairy cattle showed high correlation between dry bulb temperature and multiple cow-specific THI indices (Hammami et al., 2013), which would support the significance of maximum temperature as a predictor. Finally, we were not able to estimate the effect of THI based on macroenvironment measurements on BRD in the study calves due to a high rate of device malfunction, which could have been avoided by redundant back-up devices or more frequent checks for such failures.

The excellent positive correlation between macroand microenvironment measures, and between on-farm weather station (macroenvironment) and NOAA daily mean temperature, suggest local weather values could be used to help evaluate or anticipate potentially stressful conditions for calves with the expectation that, depending on the housing and heat-abatement practices, heat stress experienced by calves may be more severe than expected for the same macroenvironment measures. A study by Ravagnolo et al. (2000) developing a heat index function found similar results in the usefulness of public weather station data for heat stress studies in cattle. However, given that maximum temperature was significantly associated with BRD in the study calves, and that the correlation between macroenvironment and NOAA maximum temperature readings was low (rho 0.714), an on-farm weather station is expected to be a better predictor of BRD. Furthermore, such environmental data should be used with the awareness that they might be discrepant from what a calf experiences at the hutch level. Indeed, a different study found significant differences between on-farm environmental conditions from data loggers placed in adult cow pens, including freestalls and tiestalls, and local weather stations (Shock et al., 2016). Weather station mean relative humidity daily summary values were not as well correlated with NOAA daily mean humidity, which might imply humidity is more location-specific and can be influenced by other environmental factors, such as flush systems beneath hutches or standing water in the calf hutch area.

One limitation of the present study was that it was conducted on facilities utilizing hutch systems and management styles common to central San Joaquin Valley. Hence, the results of our study may not be generalizable to other calf housing and management styles (e.g., plastic hutches, group housing), calves postweaning, or to regions with dissimilar climates. The utilization of a clinical scoring system to assess the outcome of BRD may have limited the accuracy of diagnosis as well, as calves with respiratory disease do not always exhibit clinical signs. The partial use of NOAA data for missing study dates' macroenvironment measures was limited to daily summary values and not specific to location. The study was able to make use of frequent follow-up assessments by trained personnel on a large number of calves. Variable frequency of clinical observation could have affected the results had the disease duration been shorter than the follow-up interval ( 2 to $3 \mathrm{~d}$ ), but our frequent observations likely reduced the chance of missing signs of disease. Another limitation of our study was sensor failure for the macroenvironment data; such failures have been reported previously (Shock et al., 2016). Sensor failures could have been avoided by use of multiple sensors at each location, more frequent data downloads, and regular replacing of sensors. Data download at proximity using Bluetooth technology could partially mitigate the additional time and effort to obtain more frequent data downloads, which can exponentially increase depending on how many sensors are used per location and number of locations. Despite potential for other limitations, such as the effects due 
to different housing, use of shade structures, and heatabatement practices, these variables were indirectly adjusted for given the effect of herd as a variable in all the study models. The study had the benefit of extensive fine-grain temperature and humidity data recorded at specific macro- and microenvironment levels for evaluating calf exposure. A conservative approach was also taken to address maximum temperatures recorded by devices that exceeded the maximum daily values captured by regional NOAA data during the study period to minimize potential mechanical error influencing results, despite the fact that higher, more location-specific temperatures than NOAA may have feasibly been achieved on a dairy or within hutches. It should be noted that when the models were run including the data out of range of the NOAA regional maximum temperatures, the associations were similar (data not shown).

Future research should include a year-round study to evaluate temperature and humidity as predictors of BRD during other seasons and further evaluate the relationship of temperature and humidity as stressful conditions on calves. It may also be useful to develop a calf-data-specific heat stress index that better takes into account the metabolic characteristics of dairy calves, their unique hutch environment, or the type of climate. Given that studies in dairy cows have shown that sufficient time during a 24 -h cycle below a certain temperature helps minimize the negative effects of a high thermal environment by allowing for heat loss (Igono et al., 1992), it would also be useful to examine the duration per day calves experienced high temperatures, humidity, or THI and how it influences development of BRD. Data from the current study showed that previous day environmental measures were not associated with BRD in study calves (data not shown). However, a larger sample size and cumulative data based on more than 1 previous day would be useful to evaluate potential cumulative effect of heat stress, or potential ability of calves to acclimate, on risk of respiratory disease.

Data from our study can help elucidate the relationship between the environment, heat stress, and development of BRD in preweaning dairy calves and inform calf management strategies to control and prevent BRD. Calves exposed to high temperatures during the day, even in regions with relatively low humidity, may be experiencing significant heat stress that predisposes them to developing BRD. Results from our study support the raising of calves with consideration for minimizing overall heat stress and predisposing conditions at the microenvironment level. The use of supplemental shade, fans, or cooling systems during hot summer months might be considered, with the additional benefit of improving calf comfort and improving feed conversion efficiency and growth due to the calf not expending additional energy to avoid overheating (Spain and Spiers, 1996; Hill et al., 2011). Moore et al. (2012) suggested that simple and cost-effective methods, such as elevating the back of plastic hutches may increase airflow and reduce carbon dioxide levels, moderating temperature and humidity within hutches and respiratory rates in calves during warm weather. Such adjustments support the effect of a hutch microenvironment formed from numerous contributing factors as well as the positive potential in modifying housing to improve calf conditions. Furthermore, steps to prevent disease in dairy calves can be economically profitable, as it has been demonstrated that calves that develop pneumonia have increased mortality before reaching calving age and slowed growth for months following treatment (Waltner-Toews et al., 1986; Donovan et al., 1998; Stanton et al., 2012). A calf's microenvironment alters what a calf experiences and its subsequent risk of BRD; hence, emphasis should be made on strategies to improve the hutch system, optimizing ventilation, and providing ample shade, spacing, cleanliness, and dryness of the ground beneath the hutches.

\section{CONCLUSIONS}

Data from this prospective cohort study showed that daily maximum temperature by itself was a significant predictor of $\mathrm{BRD}$ in preweaning dairy calves during summer months at the macro- and microenvironment level. The strength of the association between maximum temperature inside the hutch, or at the microenvironment level, and BRD was greater than that in the surrounding macroenvironment, suggesting that hutch systems may have a distinct microenvironment influencing a calf's exposures and predisposition to BRD. In both micro- and macroenvironments, daily maximum humidity was not significantly associated with BRD, and temperature and humidity may function separately as predictors of stressful environmental conditions for calves. Although maximum THI was significantly associated with risk of $\mathrm{BRD}$, the magnitude of the association was weaker than that of maximum temperature and BRD. As a result, a heat index specific to calf response within the hutch environment or to a particular climate would be more suitable to predict heat stress and risk of BRD in hot climates similar to that of California.

\section{ACKNOWLEDGMENTS}

The authors acknowledge the owners and calf caretakers at the study premises, Deniece Williams and Paul Rossitto (Veterinary Medicine Teaching and Research 
Center, School of Veterinary Medicine, University of California-Davis, Tulare), for technical assistance. Funding for this project was provided by the American Association of Bovine Practitioners (AABP, Ashland, $\mathrm{OH})$ and the University of California Agriculture and Natural Resources (ANR, Oakland, CA).

\section{REFERENCES}

Aly, S. S., W. J. Love, D. R. Williams, T. W. Lehenbauer, A. V. Eenennaam, C. Drake, P. H. Kass, and T. B. Farver. 2014. Agreement between bovine respiratory disease scoring systems for preweaned dairy calves. Anim. Health Res. Rev. 15:148-150. https:// doi.org/10.1017/S1466252314000164.

Armstrong, D. V. 1994. Heat stress interaction with shade and cooling. J. Dairy Sci. 77:2044-2050. https://doi.org/10.3168/jds.S0022 -0302(94)77149-6.

Autio, T., T. Pohjanvirta, R. Holopainen, U. Rikula, J. Pentikäinen, A. Huovilainen, H. Rusanen, T. Soveri, L. Sihvonen, and S. Pelkonen. 2007. Etiology of respiratory disease in non-vaccinated, non-medicated calves in rearing herds. Vet. Microbiol. 119:256265. https://doi.org/10.1016/j.vetmic.2006.10.001.

Bertagnon, H. G., G. V. Z. Esper, M. P. Emanuelli, and L. G. Pellegrine. 2011. Influência meteorológica no leucograma e na população citológica do trato respiratório de bezerros. Pesqui. Vet. Bras. $31: 244-246$.

Bohmanova, J., I. Misztal, and J. Cole. 2007. Temperature-humidity indices as indicators of milk production losses due to heat stress. J. Dairy Sci. 90:1947-1956. https://doi.org/10.3168/jds.2006-513.

Box, G. E. P., and P. W. Tidwell. 1962. Transformation of the independent variables. Technometrics 4:531-550. https://doi.org/10 $.2307 / 1266288$.

Broucek, J., P. Kisac, and M. Uhrincat. 2009. Effect of hot temperatures on the hematological parameters, health and performance of calves. Int. J. Biometeorol. 53:201-208. https://doi.org/10.1007/ s00484-008-0204-1.

Buczinski, S., G. Forté, D. Francoz, and A.-M. Bélanger. 2014. Comparison of thoracic auscultation, clinical score, and ultrasonography as indicators of bovine respiratory disease in preweaned dairy calves. J. Vet. Intern. Med. 28:234-242. https://doi.org/10.1111/ jvim. 12251.

Callan, R. J., and F. B. Garry. 2002. Biosecurity and bovine respiratory disease. Vet. Clin. North Am. Food Anim. Pract. 18:57-77. https://doi.org/10.1016/s0749-0720(02)00004-x.

Carroll, J. A., and N. E. Forsberg. 2007. Influence of stress and nutrition on cattle immunity. Vet. Clin. North Am. Food Anim. Pract. 23:105-149. https://doi.org/10.1016/j.cvfa.2007.01.003.

Carter, B. H., T. H. Friend, S. M. Garey, J. A. Sawyer, M. B. Alexander, and M. A. Tomazewski. 2014. Efficacy of reflective insulation in reducing heat stress on dairy calves housed in polyethylene calf hutches. Int. J. Biometeorol. 58:51-59. https://doi.org/10.1007/ s00484-012-0623-x.

Davis, C. L., and J. K. Drackley. 1998. The Development, Nutrition, and Management of the Young Calf. Iowa State University Press, Ames.

Dikmen, S., and P. Hansen. 2009. Is the temperature-humidity index the best indicator of heat stress in lactating dairy cows in a subtropical environment? J. Dairy Sci. 92:109-116. https://doi.org/10 .3168/jds.2008-1370.

Divers, T. J., and S. Peek. 2007. Rebhun's Diseases of Dairy Cattle. 2nd ed. Saunders Elsevier Health Sciences, St. Louis, MO.

Donovan, G. A., I. R. Dohoo, D. M. Montgomery, and F. L. Bennett. 1998. Calf and disease factors affecting growth in female Holstein calves in Florida, USA. Prev. Vet. Med. 33:1-10. https://doi.org/ 10.1016/s0167-5877(97)00059-7.

Fleiss, J. L., B. Levin, and M. C. Paik. 2003. The measurement of interrater agreement. Page 604 in Statistical Methods for Rates and Proportions. 3rd ed. Wiley, New York, NY.
Gorden, P. J., and P. Plummer. 2010. Control, management, and prevention of bovine respiratory disease in dairy calves and cows. Vet. Clin. North Am. Food Anim. Pract. 26:243-259. https://doi.org/ 10.1016/j.cvfa.2010.03.004.

Griffin, D., M. Chengappa, J. Kuszak, and D. S. Mcvey. 2010. Bacterial pathogens of the bovine respiratory disease complex. Vet. Clin. North Am. Food Anim. Pract. 26:381-394. https://doi.org/ 10.1016/j.cvfa.2010.04.004.

Hammami, H., J. Bormann, N. M'Hamdi, H. Montaldo, and N. Gengler. 2013. Evaluation of heat stress effects on production traits and somatic cell score of Holsteins in a temperate environment. J. Dairy Sci. 96:1844-1855. https://doi.org/10.3168/jds.2012-5947.

Hill, T. M., H. Bateman, J. Aldrich, and R. Schlotterbeck. 2011. Comparisons of housing, bedding, and cooling options for dairy calves. J. Dairy Sci. 94:2138-2146. https://doi.org/10.3168/jds.2010-3841.

Igono, M. O., G. Bjotvedt, and H. T. Sanford-Crane. 1992. Environmental profile and critical temperature effects on milk production of Holstein cows in desert climate. Int. J. Biometeorol. 36:77-87. https://doi.org/10.1007/bf01208917.

IPCC. 2014. Climate Change 2014: Impacts, Adaptation, and Vulnerability. Part A: Global and Sectoral Aspects. Contribution of Working Group II to the Fifth Assessment Report of the Intergovernmental Panel on Climate Change. Cambridge University Press, Cambridge, UK.

Johnson, H. D., A. C. Ragsdale, and I. L. Berry and M. D. Shanklin. 1962. Effect of various temperature-humidity combinations on milk production of Holstein cattle. Missouri Agric. Exp. Sta. Res. Bull. 791, Columbia, MO.

Lago, A., S. Mcguirk, T. Bennett, N. Cook, and K. Nordlund. 2006. Calf respiratory disease and pen microenvironments in naturally ventilated calf barns in winter. J. Dairy Sci. 89:4014-4025. https:/ /doi.org/10.3168/jds.S0022-0302(06)72445-6.

Lammers, B. P., J. W. Vankoot, A. J. Heinrichs, and R. E. Graves. 1996. The effect of plywood and polyethylene calf hutches on heat stress. Appl. Eng. Agric. 12:741-745. https://doi.org/10.13031/ 2013.25707.

Love, W. J., T. W. Lehenbauer, A. L. V. Eenennaam, C. M. Drake, P. H. Kass, T. B. Farver, and S. S. Aly. 2016. Sensitivity and specificity of on-farm scoring systems and nasal culture to detect bovine respiratory disease complex in preweaned dairy calves. J. Vet. Diagn. Invest. 28:119-128. https://doi.org/10.1177/ 1040638715626204 .

Love, W. J., T. W. Lehenbauer, P. H. Kass, A. L. V. Eenennaam, and S. S. Aly. 2014. Development of a novel clinical scoring system for on-farm diagnosis of bovine respiratory disease in pre-weaned dairy calves. PeerJ 2:e238. https://doi.org/10.7717/peerj.238.

Macaulay, A. S., G. Hahn, D. Clark, and D. Sisson. 1995. Comparison of calf housing types and tympanic temperature rhythms in Holstein calves. J. Dairy Sci. 78:856-862. https://doi.org/10.3168/jds .s0022-0302(95)76698-x.

Mellado, M., E. Lopez, F. Veliz, M. D. Santiago, U. Macias-Cruz, L. Avendaño-Reyes, and J. Garcia. 2014. Factors associated with neonatal dairy calf mortality in a hot-arid environment. Livest. Sci. 159:149-155. https://doi.org/10.1016/j.livsci.2013.11.019.

Mitlöhner, F. M., M. L. Galyean, and J. J. Mcglone. 2002. Shade effects on performance, carcass traits, physiology, and behavior of heat-stressed feedlot heifers. J. Anim. Sci. 80:2043-2050. https:// doi.org/10.2527/2002.8082043x.

Moore, D. A., J. Duprau, and J. Wenz. 2012. Short communication: Effects of dairy calf hutch elevation on heat reduction, carbon dioxide concentration, air circulation, and respiratory rates. J. Dairy Sci. 95:4050-4054. https://doi.org/10.3168/jds.2012-5397.

Nardone, A., B. Ronchi, N. Lacetera, M. Ranieri, and U. Bernabucci. 2010. Effects of climate changes on animal production and sustainability of livestock systems. Livest. Sci. 130:57-69. https://doi .org/10.1016/j.livsci.2010.02.011.

National Oceanic and Atmospheric Administration. 1976. Livestock hot weather stress. Regional Operations Manual Letter C-31-76. US Dep. Commerce, Natl. Oceanic and Atmospheric Admin., Natl. Weather Service Central Region, Kansas City, MO. 
Neuwirth, J. G., J. K. Norton, C. A. Rawlings, F. N. Thompson, and G. O. Ware. 1979. Physiologic responses of dairy calves to environmental heat stress. Int. J. Biometeorol. 23:243-254. https://doi org $/ 10.1007 / \mathrm{bf01553775.}$

Radostits, O. M., I. G. Mayhew, and D. M. Houston. 2000. Veterinary clinical examination and diagnosis. Pages 151-177 in Clinical Examination of Cattle and Calves. WB Saunders, London, UK.

Ravagnolo, O., I. Misztal, and G. Hoogenboom. 2000. Genetic component of heat stress in dairy cattle, development of heat index function. J. Dairy Sci. 83:2120-2125. https://doi.org/10.3168/jds .S0022-0302(00)75094-6.

Roland, L., M. Drillich, D. Klein-Jöbstl, and M. Iwersen. 2016. Invited review: Influence of climatic conditions on the development, performance, and health of calves. J. Dairy Sci. 99:2438-2452. https: //doi.org/10.3168/jds.2015-9901.

Scheaffer, R. L., W. Mendenhall, R. L. Ott, and K. G. Gerow. 2012. Elementary Survey Sampling. 7th ed. Brooks/Cole, Boston, MA.

Shock, D. A., S. Leblanc, K. Leslie, K. Hand, M. Godkin, J. Coe, and D. Kelton. 2016. Studying the relationship between on-farm environmental conditions and local meteorological station data during the summer. J. Dairy Sci. 99:2169-2179. https://doi.org/10.3168/ jds.2015-9795.

Spain, J. N., and D. Spiers. 1996. Effects of supplemental shade on thermoregulatory response of calves to heat challenge in a hutch environment. J. Dairy Sci. 79:639-646. https://doi.org/10.3168/ jds.S0022-0302(96)76409-3.

Stanton, A. L., D. Kelton, S. Leblanc, J. Wormuth, and K. Leslie. 2012. The effect of respiratory disease and a preventative antibiotic treatment on growth, survival, age at first calving, and milk production of dairy heifers. J. Dairy Sci. 95:4950-4960. https://doi .org/10.3168/jds.2011-5067.

Stott, G. H., F. Wiersma, B. Menefee, and F. Radwanski. 1976. Influence of environment on passive immunity in calves. J. Dairy Sci.
59:1306-1311. https://doi.org/10.3168/jds.S0022-0302(76)84360 $-3$.

Stull, C. L., L. Messam, C. Collar, N. Peterson, A. Castillo, B. Reed, K. Andersen, and W. Verboort. 2008. Precipitation and temperature effects on mortality and lactation parameters of dairy cattle in California. J. Dairy Sci. 91:4579-4591. https://doi.org/10.3168/ jds.2008-1215.

USDA-APHIS. 2007. Dairy 2007, Part I: Reference of Dairy Cattle Health and Management Practices in the United States, 2007. USDA-APHIS-VS, CEAH, Fort Collins, CO. \#N480.1007.

USDA-APHIS. 2012. Dairy Heifer Raiser 2011: A Study of Operations that Specialize in Raising Dairy Heifers. USDA-APHIS-VS, CEAH, National Animal Health Monitoring System (NAHMS), Fort Collins, CO. \#613.1012.

Waltner-Toews, D., S. W. Martin, and A. H. Meek. 1986. The effect of early calfhood health status on survivorship and age at first calving. Can. J. Vet. Res. 50:314-317.

Wathes, C. M., C. D. Jones, and A. J. Webster. 1983. Ventilation, air hygiene and animal health. Vet. Rec. 113:554-559.

West, J. W. 2003. Effects of heat-stress on production in dairy cattle. J. Dairy Sci. 86:2131-2144. https://doi.org/10.3168/jds.S0022 $-0302(03) 73803-\mathrm{x}$.

Williams, R. L. 2000. A note on robust variance estimation for clustercorrelated data. Biometrics 56:645-646. https://doi.org/10.1111/j .0006-341x.2000.00645.x.

Windeyer, M. C., K. Leslie, S. Godden, D. Hodgins, K. Lissemore, and S. Leblanc. 2014. Factors associated with morbidity, mortality, and growth of dairy heifer calves up to 3 months of age. Prev. Vet. Med. 113:231-240. https://doi.org/10.1016/j.prevetmed.2013 .10 .019 . 


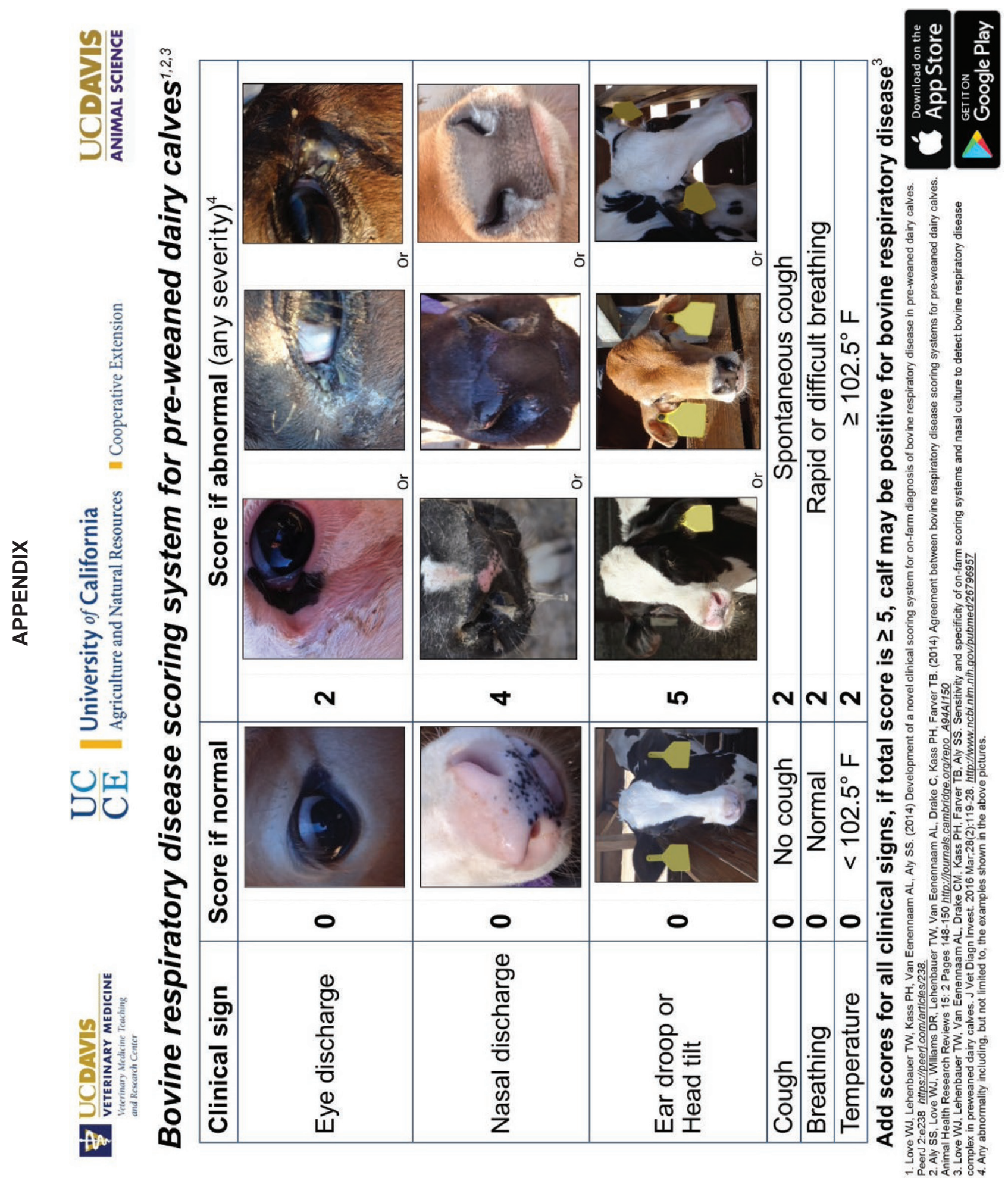

